Paper ID \#17822

\title{
Engagement in Practice: Unlocking STEM as a Career Choice for Middle School Females in a Rural School District
}

\section{Dr. Nirmala Prakash, Florida Atlantic University}

Nirmala Prakash (Ramlakhan), Ph.D. Professional Preparation University of Central Florida, Bachelor of Science in Biology B.S. 2002 University of Central Florida, Masters of Science in Health Science M.S. 2005 University of Central Florida, Doctorate in Science Education Ph.D. 2012

Appointments/Professional Experience 2015-present: Associate Research Professor of Clinical Biomedical Science: Charles E. Schmidt College of Medicine, Florida Atlantic University 2014-present: Assistant Director of Diversity and Inclusion: Charles E. Schmidt College of Medicine, Florida Atlantic University 2010-2012 Vice President of Strategic Initiatives and Research: Workforce Central Florida/USDOL 2008-2010 Director or STEM and New and Emerging Industries Special Projects: Workforce Central Florida/USDOL 2007-2008 Education Special Project Manager: Workforce Central Florida/USDOL 20052007 Science Department Chairperson: Orange County Public Schools; Orlando Florida 2002-2007 Physics and Biology Teacher: Orange County Public Schools; Orlando Florida

Selected Publications 2013 American Society of Engineering Education. Dagley, M., Ramlakhan,N., Georgiopoulos, M., Young, C. "Establishing a Women's Mentorship Network in a STEM Learning Community."

Dieker, L., Grillo, K., \& Ramlakhan, N. (2012). The use of virtual and simulated teaching and learning environments: Inviting gifted students into science, technology, engineering, and mathematics careers (STEM) through summer partnerships. Gifted Education International, 28(1), 96-106.

Ramlakhan, N., (2012). A comparative investigation of career readiness and decidedness in first year STEM majoring students participating in a stem mentoring program imbedded in a living-learning community with focused data on female STEM students. (Doctoral dissertation). Available from ProQuest Dissertations and Theses database.

Selected Papers/Presentations Conference paper \& presentation: Ramlakhan, N., American Educational Research Association. "A comparative investigation of career readiness and decidedness in first year STEM majoring students participating in a stem mentoring program imbedded in a living-learning community with focused data on female STEM students." 2014

Conference organizer, paper \& presentation: Ramlakhan, N., National Science Foundation STEPWork Conference Organizer and Presenter: "Achieving STEM Sustainability through USDOL Partnerships" 2014

Conference paper \& presentation: Association of Science Teachers Conference Paper: Ramlakhan, N., "Girls Excelling in Math and Science: Using STEM Mentorship to Increase Female Retention" (pilot data) 2011

Conference paper \& presentation: National Science Foundation Conference Paper: Ramlakhan, N., "Sustainability and Institutionalization of Undergraduate Research Experiences" 2011

Conference paper \& presentation: National Science Teachers Association National Conference. Ramlakhan, N.,"Using Industry Partnership to Increase STEM Initiative Success" 2010

Synergistic Activities • Member(2012-present): National Science Teachers Association, Association of Science Teacher Educators, Florida Chamber, STEMflorida, Palm Beach STEM Council; Industry Advisory Council Member 2010-2013: Digital Media, STEM for Orange County Public Schools, Career and Technical Education and Seminole College • Collaborative Projects (2007-2013) - Orange, Lake, Sumter, Seminole and Osceola County Public Schools, Lockheed Martin, Electronic Arts, Girl Scouts, Junior Achievement, Prism, Orlando Science Center, University of Central Florida, Valencia, Seminole and Lake Sumter Colleges • Coordinator of Industry Expert Review Committee: 2008 Math Sunshine State Standards • Member of the Strategic Planning Committee (2011-2012) - Florida Center for Research in Math and Science Education • Medical Scholars Program (2014-present) - Florida A\&M University, MCAT prep curriculum developer 
Collaborators (11)

Andrew Daire University of Texas; Melissa Dagley, University of Central Florida; Lisa Dieker, University of Central Florida; Michael Georgiopoulos University of Central Florida; Kelly Grillo, University of Central Florida; Bobbi Jeanpierre, University of Central Florida; Leslie Hielema, Florida Institute of Technology; Nancy Romance, Florida Atlantic University; Julie Servoss, Florida Atlantic University; Michael Smith, Florida A\&M University; Cynthia Young, University of Central Florida;

\section{Ms. Rachel Tobillo, Charles E. Schmidt College of Medicine at Florida Atlantic University}

Rachel Tobillo is a 2nd year medical student at Florida Atlantic University (FAU) in Boca Raton, Florida. She currently serves as the Health Careers Outreach Program (HCOP) Student Leader and as the Vice President of the Competency in Medical Spanish organization on campus. She is also the co-founder of a new initiative at FAU that aims to integrates the arts into medicine and patient care. 


\section{Engagement in Practice: Unlocking STEM as a Career Choice for Middle School Females in a Rural School District}

\section{Introduction}

STEM talent and career development is a national priority for the U.S. due to workforce skills gaps and competitiveness on the global arena. One explanation for the gaps in STEM talent and career development is the high attrition and low recruitment rates of STEM students and workers, particularly of females. For example, although women make up almost half of the U.S. workforce, they account for only $24 \%$ of the U.S. STEM workforce (Beede et al., 2011; NSF, 2010, Ramlakhan, 2012). Known gender disparities in psychological factors influencing educational and career choice such as attitudes, independence, and self-perception of ability provide a potential explanation for lower recruitment and retention rates of females and minorities in STEM (Bandura, 1986; Betz \& Hackett, 1983, Maple \& Stage, 1991; Schoon, 2001; Seymour \& Hewitt, 1997). Research states student involvement and exposure to mathematics and sciences at young ages is crucial for STEM career development, especially for socially disadvantaged groups such as women, ethnic minorities, and economically disadvantaged groups (Callahan \& Reis, 1996; Graham, 1994, Hanson, 1994; Trusty, 2002). These psychological and socioeconomic factors explain why researchers from a large urban university, two private foundations, and a high-tech medical simulation center united to form the GEMS partnership, which endeavors to unlock STEM as a career choice for middle school females in a rural school district.

\section{Literature Review}

Employers in the United States have more job vacancies in STEM than there are qualified people to fill those positions. The inadequate pipeline of workers served as the rationale for former President Obama to institute a national STEM initiative in 2012 focusing on recruitment, retention, and training needs from cradle to career. His national agenda emphasized (a) recruitment of students into STEM courses of study in K-16, (b) recruitment of dislocated workers and females into STEM careers, and (c) retention of K-16 students in STEM majors (Obama for America, 2012; U.S. DOLETA 2010, 2011, Ramlakhan, 2012). Findings from this economic plan, coupled with other research and literature, recognizes the need for STEM career and talent development in underrepresented populations. Beyond the need to direct resources towards underrepresented populations, the literature supports integrating government, industry, and community partnerships into STEM education and recruitment efforts. The World Declaration on Education for All in 1990 initiated a call for "new and revitalized partnerships at all levels" to provide basic education for all. The Declaration established the importance of partnerships in basic education, which by extension, demonstrates the need for partnerships in STEM education and recruitment. Rationales and benefits of partnership, as outlined by Bray (2000), include shared experiences and expertise, mutual support, division of labor, increased effectiveness, and increased resources. In other words, collaboration allows partners to support each other in achieving a common goal and to focus on the tasks they do best. The importance of partnerships in education is routinely cited in the President's Council of Advisors on Science and Technology (PCAST) report on STEM education (2010), the National Impact Report of the NSF's Math and Science Partnership Program (2010), and the Information Technology \& Innovation Foundation's report on STEM education (2010). Pulling from the literature, the 
GEMS intervention revolves around a partnership comprised of researchers from a large urban university, two private foundations, a high-tech medical simulation center, and a rural school district.

Effective STEM programming targets the root of the problem; low undergraduate recruitment and retention which partially explains the supply shortfalls within STEM career development. However, issues underlying low undergraduate recruitment may begin during middle school. Education research strongly urges that students begin receiving information on educational and career planning in the eighth grade (Mau 1995, George 1990). The transition from middle to high school is a turning point in a students' education, they must decide whether to take a vocational track, a college preparatory track, or other. Unfortunately, many may not be equipped to make a decision due to a variety of career-decision making difficulties (Mau 1995, U.S. Department of Labor, 1992, Gati, 1996).

Reducing dysfunctional career thinking can be used as a strategy to increase retention in STEM. Dysfunctional career thinking is based on the concept that difficulties surrounding the career decision-making process may prevent individuals from making a sound decision and may even result in indecision. These difficulties can consist of negative beliefs or thoughts that may "decrease the individual's self-esteem and perceived self-efficacy, [and thus] ...decrease the individual's confidence in his or her ability to make decisions" (Kleiman, 2004). Gati (1996) developed a taxonomy of career decision-making difficulties to explain possible sources of vocational indecision. Examples of difficulties include lack of information about occupations, lack of information about oneself, internal conflicts, external conflicts, and dysfunctional beliefs, such as irrational expectations about the career-decision making process itself.

Dysfunctional career thinking appears to have a large impact on STEM career choice in females. In a meta-analysis of literature exploring the absence of women in STEM, the proposed explanations for shortfalls include: (1) girls' poor attitude toward science and lack of positive experiences with science in childhood, (2) the absence of female scientists/engineers as role models, (3) the 'chilly climate' for girls/women in science classes, and (4) cultural pressure on girls to conform to traditional gender roles (Blickenstaff 2005). These explanations provide rationale for increased levels of dysfunctional career thinking in females, resulting in less females entering or remaining in a STEM career. Researchers have suggested that the lack and/or loss of female STEM talent at all levels of the career pipeline is to blame. Two reasons have been identified to explain why fewer females and minorities receive bachelor's degrees in STEM fields: (1) both groups are less likely to pick a STEM major initially, and (2) if they do, are less likely to persist in that major (Chen \& Weko, 2009; Griffith, 2010, Ramlakhan, 2012). Tyson et al. (2007) corroborates that "women, Black and Hispanic students, and students with lower socioeconomic status (SES) typically do not pursue STEM degrees at the same rate as men, White and Asian students, and students with higher SES". Therefore, interventions aimed at both female and minority populations are necessary. Given the aforementioned rationale, GEMS focuses on unlocking STEM as a career choice for middle school females in a rural district.

\section{Methodology}

The GEMS intervention aimed to reduce dysfunctional career thinking in middle school females through a STEM career exploration program. The intervention is based on a STEM adaptation of 
an empirically tested decision-theory model developed by Gati et al. (1996) that reflects individuals' career readiness and decidedness difficulties. GEMS focuses specifically on addressing the second category of Gati's model, lack of information, including lack of knowledge about the process of making a career decision, lack of information about self, various occupations, and ways of obtaining additional information (Gati, 1996, Ramlakhan, 2012).

The intervention took seven months, involved 143 participants, and occurred in eighth grade science classrooms. All students participated in career surveys and activities in the classroom beginning in October where they researched desired careers, high school pathways (college preparation, career academy, or general diploma), local hiring companies, salary levels, and educational requirements (bachelor or associate degrees, certifications or technical schools). Career thinking constructs were assessed pre- and post- intervention using the Career Decision Scale (CDS) and a general career interest survey administered by science teachers.

In February, faculty from a local public university led a STEM career exploration workshop day for all 143 eighth grade females. The faculty researcher designed the workshops based on responses received from a self-generated "STEM Career Choice Survey" for 143 females. The survey, administered and tallied by the classroom teacher, gauged student desire to attend college, student understanding of post-secondary career paths, student understanding of how to attend college, and major/career interest. Of the 143 females, 101 surveys were completed and submitted. One hundred percent of respondents expressed the desire to go to college and the belief that they could get in to college. However, more than $50 \%$ of survey responses demonstrated that the girls did not understand how to apply for college and have not identified a desired major. Following the survey the researcher formulated a workshop day that addressed specific outcomes as identified by the teacher, survey, literature, partners and principal. The workshop day began with a broad STEM career exploration whole-group session, covering topics such as what is STEM, why are STEM careers in demand, what are industry certifications and why are they helpful, wages, STEM career ladders and educational timelines. Breakout sessions followed the whole group presentation and Q\&A led by high ranking females in the school district such as the superintendent, assistant superintendent, guidance counselors and other staff. Students, divided into groups of ten, participated in breakout sessions where they learned how to access their chosen STEM career by creating a college roadmap — a 15 year educational and career plan for their future. Follow-up activities and in-classroom work allowed students to fully plan and understand two of their chosen STEM career pathways. Culminating this 7-month program, students had the opportunity to take a field trip to a local public university's main campus for a tour, financial aid and admissions workshops and to engage in a medical lab at the university's Simulation Center.

Middle school teachers in hard copy administered assessments during students' science classes in February 2016 and May 2016, before and after the STEM exploration workshop day. The teachers were trained on assessment delivery by the researcher using the assessment manual as the guide for training. Teachers were instructed on delivery and assessment usage. Completed assessments were hand-delivered or mailed to the researcher for scoring and data entry by trained research assistants. The researcher noted and excluded incomplete pre- and post-assessments. Various reasons for missing assessment included: change of school, absenteeism, and student desire to not complete the assessment. Data analysis followed. 
Career Decision Scale (CDS). The Career Decision Scale (CDS) is a validated and reliable assessment that provides an estimate of career indecision and an outcome measure to determine the effects of relevant interventions. The validity of the CDS has specifically been examined in the context of treatment studies, whose results indicated "the potential sensitivity of the [CDS] for identifying changes brought about through interventions designed to reduce career indecision" (Osipow, 1986). The 19-item assessment allows students to indicate how closely each statement describes their thoughts related to educational and career plans on a scale of 1-4. The certainty scale measures the degree of certainty a student feels about his or her decision about a college major and career. The indecision scale provides a measure of career indecision. Item 19 is open-ended, allowing the student to clarify or provide additional information about his or her career decision making (Osipow \& Winer, 1996, Ramlakhan, 2012). Six different studies conducted between 1976 and 1985 found factors served as good predictors of career decision making and identified those individuals who would benefit from career counseling. A correlation to ACDM, the assessment of career decision making (Buck \& Daniels, 1985) yielded a correlation $r=-.265, p=.004$. Therefore, researchers concluded that the CDS has acceptable levels of test-retest reliability and norms for grade school level students. The validity is strong; the instrument can differentiate between career decision and indecision.

Assumptions and Limitations. A limitation of this study resulted from the lack of a truly experimental research design. The sample was not randomized. Participants in the intervention were selected based on their enrollment at the middle schools within the aforementioned rural school district. In addition, the research design and methodology in its entirety rests on the assumption that dysfunctional career thinking plays a major role in career choice, with Gati's taxonomy of career decision-making difficulties as foundational support (1996). In regards to the assessment tool itself, some items on the CDS have multiple descriptors and statements within a single item, which can affect their relatability and the accuracy of students' responses. For example, Item 7 states, "Until now, I haven't given much thought to choosing a career. I feel lost when I think about it because I haven't had many experiences in making decisions on my own and I don't have enough information to make a career decision right now". Students may strongly agree with the first part but disagree with the statement in its entirety, which would make it difficult to gauge how closely the statement reflects his or her feelings. Slaney agrees that the multi-component nature of several items, which "[describe] different aspects of a barrier to decision-making" may explain the "lack of consistency of the factor structure across studies" (1985).

The CDS is also not specific to STEM careers. Therefore, any change in the data gathered from the certainty and indecision subscales was based on the students' career plans, which may or may not be STEM related, at the time of administration. However, since Gati's decision-theory model underlies the entire research design and applies to careers in general, an assessment tool that measures students' levels of dysfunctional career thinking should, by extension, measure students' levels of dysfunctional thinking regarding STEM careers (1996). In addition, an extensive history of studies have supported the validity of the CDS. Various "treatment studies" examining the responsiveness of the CDS to career counseling interventions "provide support for the hypothesis that groups exposed to treatment for vocational indecision would be less undecided than before treatment" (Osipow, 1986). Given the GEMS intervention's goal to reduce career indecision, the CDS is an appropriate assessment tool for this study. 


\section{Data Analysis}

This study aims to answer: What affect did the GEMS initiative have on career decidedness as measured by the Career Decision Scale? The researcher used the CDS assessment and its subscales to evaluate dysfunctional career thinking and determine career certainty and indecision pre- and post-intervention. The quantitative data gathered included assessment administrations in February and May of 2016. Assessments were administered by middle school science teachers during class time. Assessments allowed participants to self-report on the following subscales: (a) career decision and (b) career indecision.

To ensure fidelity of treatment, trained faculty from a local public university and trained female executives from the school district worked together to administer the STEM career exploration intervention. Middle school science teachers were trained on assessment delivery by the researcher who was trained using the assessment manuals. Upon assessment, trained research assistants collected, scored and entered data. The researcher trained all research assistants and maintained oversight during the intervention. Participants were permitted to not test without repercussion. Incomplete pre- and post-assessments were excluded from the data set. All February administrations of CDS were inputted together; May data were inputted in the same manner. Variables were then merged to make a complete data set.

Of the 143 students expected to be in the sample, 82 students fully completed the pre- and postassessment. Accordingly, this means that 68 potential sources of data were lost because of incomplete questionnaires and/or missing pre- or post-assessments. Data from the CDS certainty subscale gathered in February was 5.55 and the data from the same subscale gathered in May was 5.54. Data from the CDS indecision subscale gathered in February was 33.35 and the data from the same subscale gathered in May was 33.04. A paired t-test using the means of the CDS certainty subscale gathered in February and May, found there was a statistically significant difference in the mean certainty score from February versus May. Based on the negative mean difference between the February and May certainty data sets, the GEMS College Roadshow initiative resulted in less career certainty. One of the limitations of the CDS is that it is not STEM-specific. This means that prior to intervention; students may have had a non-STEM career interest, may have already been interested in a STEM field, or may have had no concrete career interest. Therefore, resulting in a variety of possibilities of the interventions' effect on career certainty. The intervention may have affected individual students' certainty regarding a nonSTEM career, a STEM career, or even their lack of interest in a specific career. Based on the CDS alone, a comparison of the pre- and post- intervention assessments cannot determine whether students are more certain about a STEM career specifically.

Responses to Item 19, the free-response section, in the pre-intervention assessment included: "I know what I want to do and I have no problem knowing what to do to get there; I like helping people but I also like dancing more. I feel a bigger passion for dancing though; ...I want a bright future. I'm trying to get good grades so I can become someone in life and make my family proud."

Responses to item 19 in the post-intervention assessment included: "I know exactly what I am good at and what I want to do, and I also have back-up ideas in case something comes up that complicates things; I would like to be a nurse or sea life rescuer but I don't know what I really want to be; I know I can do a more challenging career, but I don't know all the options. Or what the actual jobs require, like hours or where you can live, or how much college would cost." 
The t-test results, along with the free responses, reflect the possibility that the GEMS College Roadshow made students less certain about their career choice because it introduced options previously thought to be inaccessible, such as a STEM career. The free responses demonstrated some students had non-STEM interests, which may have caused them to feel less certain about their original career choice during the post-intervention assessment. The lack of career certainty post-intervention demonstrates that middle school students may need more depth of exposure to STEM careers and step-by-step guidance, as reflected by one of the students' post-assessment open-ended responses.

Table 1. Comparison of Means of CDS Certainty and Indecision Subscales in February vs. May

\begin{tabular}{r|ll}
\hline & February & May \\
Certainty & 5.55 & 5.54 \\
Indecision & 33.35 & 33.04
\end{tabular}

\section{Conclusion}

The GEMS partnership is comprised of parents, principal, school district, local university researchers, two private foundations, and a high-tech simulation center. The intervention sought to narrow the STEM supply and demand gap by increasing recruitment of underrepresented populations. Engaging 143 diverse and economically disadvantaged female eighth graders from a rural school district in a STEM career exploration program, the study answered the existing literature's call for more STEM outreach programs. Data analysis conclusions included: (1) Students showed no significant change in career indecision and (2) showed a significant decrease in career certainty. Preliminary results further confirmed the need for STEM interventions for middle school females and identified the need to start outreach programs at an earlier grade level. Within the $8^{\text {th }}$ grade, students select a high school career track leaving limited time for extensive STEM career exploration. Prior to the intervention, no career exploration occurred at the middle school. Limited understanding of STEM careers depressed female enrollment in STEM high school career tracks. Moving forward, the district superintendent aims to expand the GEMS pilot program to all the middle schools in the district to counteract this problem. Additionally, teachers and administrators recognized the need to educate disadvantaged middle school males on their career options as well.

The goal of GEMS, to spark interest in a career that students may have previously considered inaccessible (i.e., a STEM career), may provide an alternative explanation for the decrease in career certainty. For example, students considering non-STEM career options may have experienced a decrease in career certainty after exploring STEM careers throughout the GEMS intervention. Therefore, the decrease in career certainty is not a concrete indication of the effectiveness of GEMS because the CDS does not account for students' baseline career thinking. A survey that elicits students' initial thoughts on career choice may resolve this issue in future research studies.

From the local university's perspective, university-sponsored outreach programs generate familiarity and potential interest in school enrollment. More specifically, a university-sponsored STEM outreach program may lead to increased university enrollment of students majoring in STEM, which fulfills both national agenda objectives and local university objectives to train and retain experts in varying fields who will contribute to the development of the local economy. Similarly, the private foundations aim to create a more diversified workforce and to encourage 
freshly trained talent to use their skills to fuel the local economy. The leadership of these foundations recognize that economic development lags when supply does not meet demand, which explains their mission to produce diverse and highly qualified individuals that can fill local STEM employment vacancies.

From a bird's eye view, the results and lessons learned from the GEMS program underscore the importance of partnerships in educational outreach programs. Advocates for basic student education - parents, teachers, school administrators - carry the initial responsibility of identifying a specific deficit in their school, district, or county that existing internal resources cannot correct. University, industry, and community partners interested in supporting outreach programs can then facilitate partnerships by informing parents and teachers of their mission statements and their available resources. The GEMS partnership arose from a networking encounter between the university outreach director and parents in the community after a speaking engagement. To initiate more of these connections, outreach directors can arrange to speak at community events, meet with administrators of at-risk schools and school districts, and create their own initiatives to support disadvantaged or historically underrepresented students. Additionally, lessons learned from this pilot program include the need for longitudinal programming, possibly through mentoring interventions, an externship, or summer camp. This study shows that STEM exploration interventions beginning in the eighth grade may not significantly reduce dysfunctional career thinking in economically disadvantaged middle school females. There is value to engaging in activities designed to introduce STEM career thinking earlier in middle school. 